\title{
Modelling and simulation of a cold storage room driven by a continuous adsorption refrigerator
}

\author{
Kolthoum Missaoui ${ }^{1,2}$, Slimane Gabsi ${ }^{2}$, Nader Frikha $^{2}$, Abdelhamid Kheiri $^{1}$, Mohammed El Ganaoui ${ }^{3}$ \\ ${ }^{1}$ Université de Lorraine, CNRS, LEMTA, F-54000 Nancy, France \\ ${ }^{2}$ Gabès University, Energy, water, Environment \& Processes (LR18ES35) laboratory, ENIG, Gabès, Tunisia \\ ${ }^{3}$ Université de Lorraine, INRA LERMAB, F-54400 Longwy, France
}

\begin{abstract}
The present work proposes a continuous solar adsorption refrigerator for a positive cold storage room of $231 \mathrm{~m}^{3}$ used for fruits and vegetables preservation and installed in the south of Tunisia. After the estimation of the storage room cooling load, which is equal to $13 \mathrm{~kW}$, a parametric study, aims to improve, the performance of the chiller is done in order to achieve the storage room need and to estimate the required heat in the refrigerator generator. A theoretical model, based on the thermodynamics of the adsorption process, heat and mass transfer within the porous medium and energy balance in the system components, is developed and a simulation with Matlab/Simulink, is carried out. The model was established and validated with the literature experimental data. A maximum coefficient of performance of 0.52 and cooling load of 22 $\mathrm{kW}$ are reached at cycle time of 800 seconds, the inlet temperatures of heating, cooling and chilled water are $85^{\circ} \mathrm{C}, 22^{\circ} \mathrm{C}$ and $15^{\circ} \mathrm{C}$, respectively.
\end{abstract}

\section{Introduction}

The cooling processes achieved by the conventional refrigeration machines consume a lot of energy, especially when it is hot. As reported by International Institute of Refrigeration the energy consumption of refrigeration and air-conditioning processes of various system kinds present $15 \%$ of the world's energy[1].

Due to the scarcity of electricity, the agriculture field in Tunisia suffers from problem of storage of natural product especially fruits and vegetables. Large amounts of products are wasted every year. Furthermore, the classical refrigeration technologies use CFCs or HCFCs, which have negative impact on the environment due to their undesirable Ozone Depletion Potential (ODP) and Global Warming Potential (GWP) levels.

In this context, thermally driven refrigeration systems using renewable energies and especially solar energy attract currently considerable attention. The coincidence between the needs of cooling power and the availability of the solar irradiation in hot regions and during hot periods makes solar refrigeration system as a great solution to overcome these problems. Another advantage of this system relates to the environmental aspect, in fact this technique does not contribute neither to global warming nor to the generation of polluting gases.

Among the different solar refrigeration technologies (Erreur! Source du renvoi introuvable.), adsorption systems are suitable choice since they can be driven by low-grade heat sources and thanks to their low environmental impact [2]. However, these systems present some drawbacks: solar adsorption refrigeration chillers generally work with a simple basic cycle that uses a single, intermittent bed. They consequently present low efficiency and low refrigeration effect so it constitutes barriers to a more use of this technology. Numerous attempts have been made in the literature to develop and design a continuous operation and to increase cycle performance and efficiency.

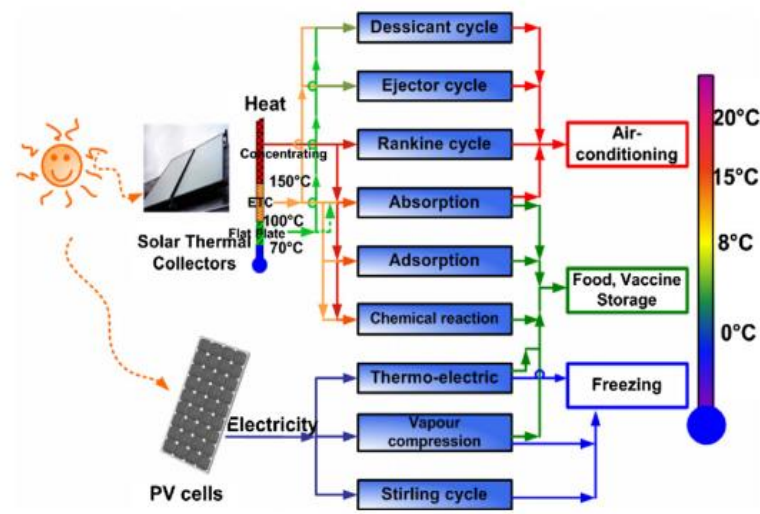

Fig.1. Solar cooling paths [3]

Maggio et al [4] demonstrated that double bed configuration allows to increase the thermal performance coefficient COP from 0.44 to 0.63 . A two dimensional numerical model describing a double bed adsorption machine is proposed, with internal heat recovery, using

\footnotetext{
Corresponding author: kolthoummissaoui@gmail.com
} 
two heat exchangers coated with a consolidated layer of zeolite 4A and water as adsorbate.

Rezk and Al-Dadah [5] studied a lumped analytical model for a two-bed silica gel adsorption chiller incorporating mass and heat recovery process. In this model, the effects of various physical parameters on the performance of the adsorption chiller were investigated. Cooling capacity is used as the objective function.

Habib et al [6] investigated the performance of a solar powered combined adsorption refrigeration cycles using the meteorological data of Singapore and Malaysia. The optimum cooling capacity, coefficient of performance (COP) and chiller efficiency are calculated in terms of cycle time, switching time, regeneration and brine inlet temperatures.

Tso et al [7] developed a composite adsorbent material, which is synthesized from activated carbon, silica gel and $\mathrm{CaCl} 2$ which demonstrates an ideal $\mathrm{COP}$ of 0.7 and an average SCP of $378 \mathrm{~W} / \mathrm{kg}$.

However, most of researchers as stated above are focusing more on improving the performance of adsorption systems by investigating the adsorbents properties and advanced cycles [8], system performance can be improved by optimization of working conditions as presented in some works .

Alam et al [8] investigated the performance of a solar silica-gel/water adsorption chiller for Tokyo climatic data and found that cycle time plays a vital role in solar adsorption chillers.

In order to improve the performance of adsorption refrigeration systems, Ntsoane et al [2] experimentally studied the capacity of a silica gel adsorption chiller working in optimum operating conditions to store fresh mangoes.

This present work is focused on improving the refrigeration performance of a continuous adsorption chiller at different cycle times, various heat water regeneration temperature and cooling water inlet temperature. After predicting its required frigorific capacity of a cold storage room used for fruits and vegetables conservation, the goal is to demonstrate the capacity of the studied continuous adsorption refrigeration system to drive it.

\section{Cold storage room modelling}

\subsection{Cooling load calculation}

The system's cooling load is the total heat that must be removed from the interior of the cold room. It is computed taking into consideration heat transfer through the walls, the stored products package heat capacities as well as the product biological heat [9]. The major heat sources as presented in Fig.2 are:
-The heat transfer rate through the walls surrounding the cooled space, the ceiling, and the floor.

- The heat transfer rate by air infiltrations.

-The heat transfer rate from the stored product.

-The heat transfer rate from machines (fans, light, rolling stock...).

The heat transfer rate due to people working inside the room.

$$
Q_{\text {tot }}=\sum_{i=1}^{8} Q_{i}
$$

The refrigerating capacity to be installed is therefore the sum of all of these heats. However, this sum had to be increased by $15 \%$ to take account of incalculable contributions and changes that the refrigeration installation must also support.

Assuming that there is no particular direct radiation contribution or additional ventilation to be expected, and based on the ASHRAE method (American Society of Heating, Refrigerating and Air-Conditioning Engineers) as presented in [10-12], a mathematical model is established in order to determine the cooling load of the studied system.

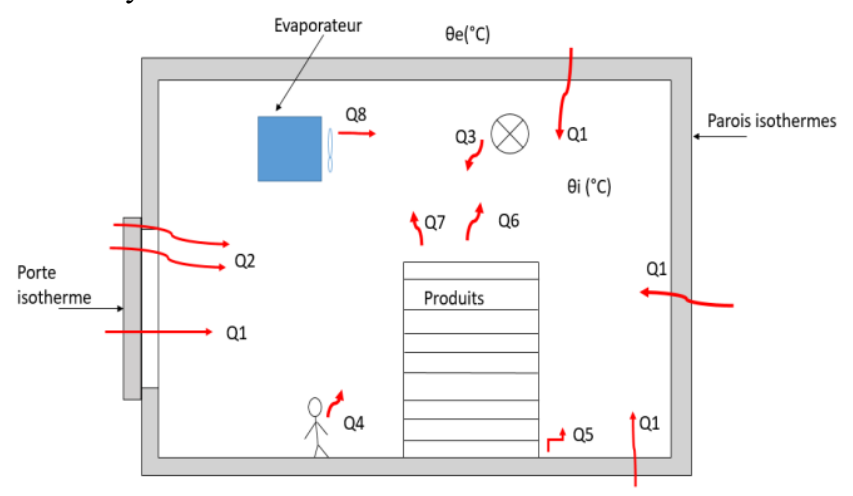

Fig.2. Thermal balance of a cold storage room

\subsection{Cold storage room working conditions}

In this study we consider a cold storage room located in Sfax, Southern zone of Tunisia, that is used to store fruits and vegetables, and particularly some local famous kinds of melon during summer months.

Fig.3 shows the annual variation of ambient temperature in the city of Sfax. This graph is obtained using the Meteonorm 7.1.3 program (Meteonorm, 2018).

It's shown that this region has a high ambient temperature in summer.

The cold room's dimensions were $7 \times 6 \times 5.5 \mathrm{~m}$ $\left(231 \mathrm{~m}^{3}\right)$ and was used to store 20 metric tons of melon at optimum storage conditions that aim to ensure the highest storage life of this fruit [13]: temperature between 9 and $13{ }^{\circ} \mathrm{C}$ and relative humidity of around $90 \%$. 
The product is put on wooden boxes with a unitary capacity of $30 \mathrm{~kg}$, stacked over wooden pallets and disposed in the cold room.

Three persons work inside the cold room for handling purposes during an average period of 2 hours per day for each person.

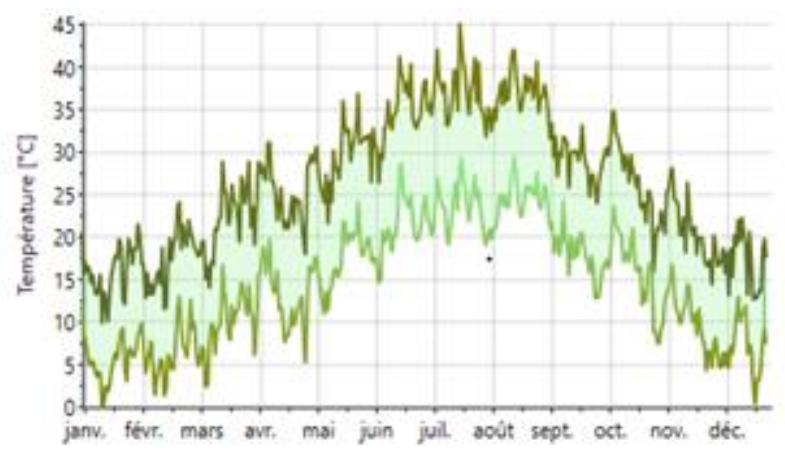

Fig.3. Daily temperature in Sfax during a year

\subsection{Computing results}

According to the Tunisian National Institute of Meteorology, the average ambient temperature in Sfax for the summer months is $35^{\circ} \mathrm{C}$. Therefore, an average ambient temperature of $35^{\circ} \mathrm{C}$ is considered, as well as a storage temperature of $9^{\circ} \mathrm{C}$.

A MATLAB code was established to predict the needed refrigeration capacity of the studied system, and permits to find that, an average power of $13 \mathrm{~kW}$ is enough for the cold room's running. The parts that Products, walls, and other heat sources respectively represent on this refrigeration needed power are depicted in Fig.4.

As shown the major input data, are the heat gained by products $(68 \%)$ then the heat gained through walls $(24 \%)$ and the rest are the heat released by lights, fans and people.

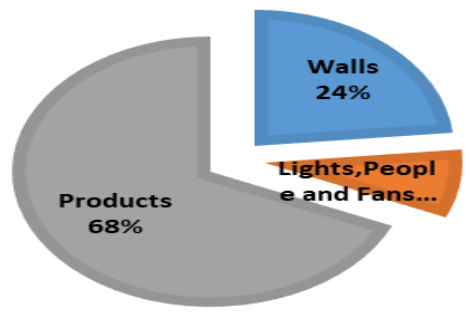

Fig.4. Cooling load distribution in the cold room.

\section{Solar adsorption refrigerator}

\subsection{Working principal}

Fig.5 shows a schematic diagram of a simple solar driven single-stage 2-bed adsorption chiller.

The driven heat source is solar radiation that is absorbed by a solar thermal collector and then transferred to the adsorption refrigeration chiller. A simple two-bed adsorption refrigeration cycle consists of an evaporator, a condenser, an expansion device, and a pair of adsorption beds (adsorber or desorber based on operating mode) which are packed with a desiccant material to desorb/adsorb the refrigerant. The considered desiccant material here is silica gel, and the refrigerant fluid is water.

The operation of an ideal adsorption chiller as presented in Fig.6 starts with the switching period, which, consists of an isosteric preheating (1-2) of the desorber (bed1) by solar hot water allowing the increase of its pressure, and a simultaneous isosteric precooling (4-3) of the adsorber (bed 2) by the cooling water to decrease its pressure. This phase continues until the pressures of bed 1 become almost equal to the condensing pressure and the pressure of the second one become almost equal to the evaporation pressure. During this phase, all the valves are closed to keep the amount of refrigerant in the reactors constant.

Next, the valve between bed 1 and the condenser is opened while the heating process is continued. Therefore the bed 1 pressure remains constant (isobaric desorption process (2-3)) and the released superheated refrigerant (water vapor) goes to the condenser.

Then, the water vapor is condensed in the condenser by transferring its heat to the cooling medium (cooling water). The saturated liquid is then expanded in an expansion valve and flows through the evaporator to absorb heat from a chilled water (cold production phase) As desorption process occurs in bed 1, the adsorption process takes place in bed 2 (3-4 process). Cooling process is continued till (4) and the valve between bed 2 and the evaporator is opened. Therefore, the bed pressure remains constant and fulfills the (4-1) process that is an isobaric adsorption process. Next, the refrigerant vapor passes from the evaporator to be adsorbed by bed 2 . When the production of cold decreases (saturation of the adsorbent in water vapour), the functions of the two compartments are switched by opening and closing valves.

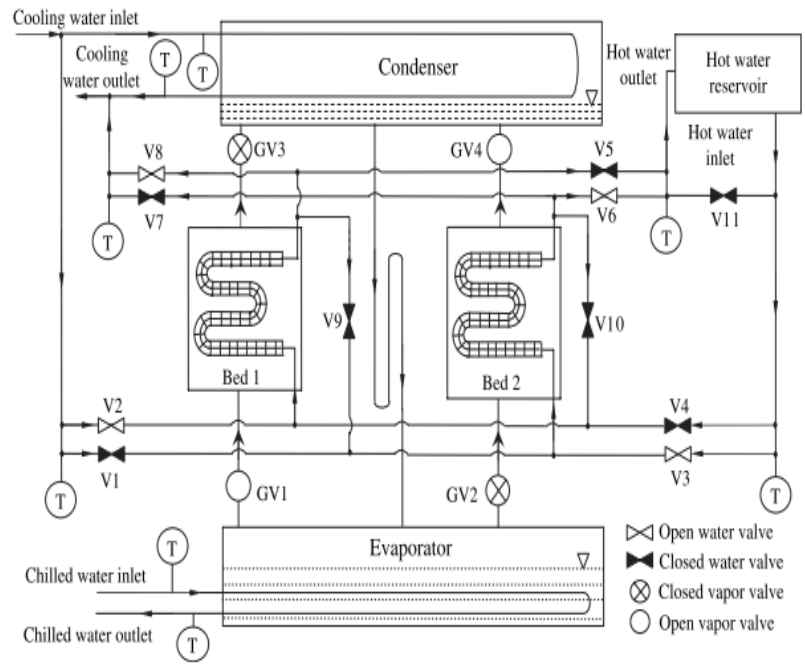

Fig. 5. Schematic diagram of a two-bed adsorption Chiller [14] 


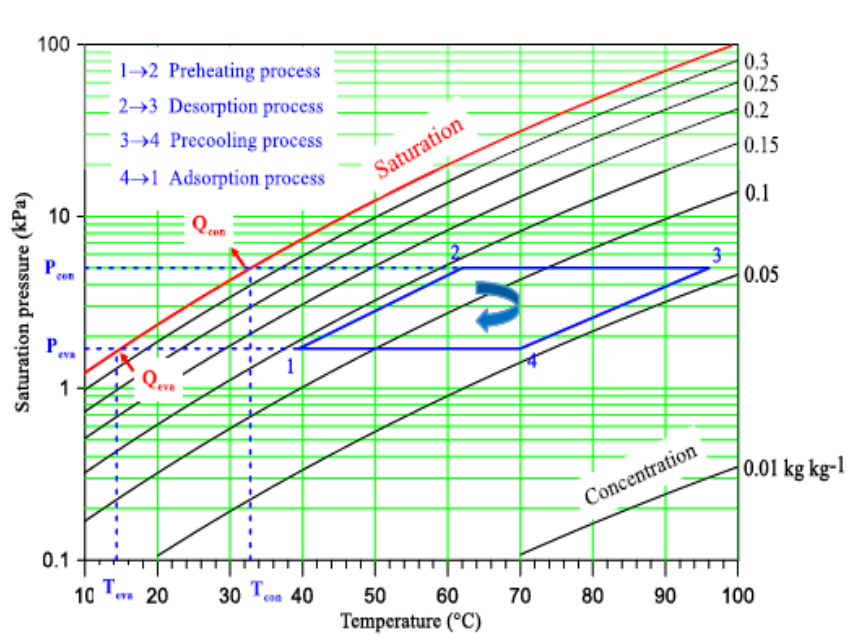

Fig.6. Dhüring diagram of an ideal adsorption chiller.

\subsection{Thermodynamic study}

Heat transfer to the desorber/adsorber beds, evaporator and condenser are estimated using LMTD method whereas the adsorption kinetics is modelled using the Linear Driving Force (LDF) model determined by Chihara and Suzuki. [15] [16]

The modelling and simulation equations and data are same as Chua et al [15].

\subsubsection{Adsorption unit}

\section{Rate of adsorption/desorption}

The rate of adsorption or desorption $(w)$ is calculated by the linear driving force kinetic equation:

$$
\frac{d w}{d t}=\mathrm{K}_{\mathrm{s}}(\mathrm{w} *-\mathrm{w})
$$

$w^{*}$ is the equilibrium amount adsorbed, which is calculated by modified Freundlich model as a function of pressure and temperature.

It is defined for silica gel/water as follow [16] :

$\mathrm{w}^{*}=0,346\left(\frac{\mathrm{P}_{\mathrm{s}}\left(T_{w}\right)}{P\left(T_{a}\right)}\right)^{1 / 1.6}$

Ps $\left(T_{w}\right)$ and $P s\left(T_{s i}\right)$ are respectively the saturated vapor pressures of the refrigerant at temperatures $T_{w}$ and adsorbent temperature $T_{a}$.

$\mathrm{K}_{\mathrm{s}}$ is the effective mass transfer coefficient inside the pores, it is given by [16]

$$
K_{s}=F_{p} \frac{D_{s}}{R_{p}^{2}}
$$

The effective diffusivity $\mathrm{D}_{\mathrm{s}}$ is defined as follow:

$$
D_{s}=D_{s o} \exp \left(\frac{-E_{a}}{R T}\right)
$$

\section{Water properties}

Saturated vapour pressure of water is given by Antoine's equation [17]:

$$
P_{\mathrm{s}}=133.32 \exp \left(18.3-\frac{3820}{\mathrm{~T}-46.1}\right)
$$

\section{Energy balance equations}

The balance energy for each equipment of the refrigerator are written by the following equations:

- Adsorber/desorber energy balance

$$
\begin{aligned}
& \left(\mathrm{m}_{\mathrm{des} / \mathrm{ad}} \mathrm{C} \mathrm{p}_{\mathrm{de} / \mathrm{ad}}+\mathrm{m}_{\mathrm{a}} \mathrm{C}_{\mathrm{a}}+\mathrm{m}_{\mathrm{a}} \mathrm{w} \mathrm{Cp}_{\mathrm{r}}\right) \frac{\mathrm{dT}}{\mathrm{dt}}= \\
& \alpha \mathrm{m}_{\mathrm{a}} \mathrm{H}_{\mathrm{ads}} \frac{\mathrm{dw}}{\mathrm{dt}}+\alpha(1-\beta) \mathrm{m}_{\mathrm{a}} \cdot \mathrm{Cp}_{\mathrm{r}, \mathrm{v}} \frac{\mathrm{dw}}{\mathrm{dt}}[\mathrm{Tev}-\mathrm{Tad}] \\
& +\dot{\mathrm{m}}_{\mathrm{f}} \mathrm{Cp}_{\mathrm{f}}\left(\mathrm{T}_{\mathrm{f}, \text { in }}-\mathrm{T}_{\mathrm{f}, \text { out }}\right)
\end{aligned}
$$

The flag $\alpha$ is equal to 0 during the switching mode and 1 during isobaric adsorption/desorption process.

$\beta$ is equal to 0 or 1 during desorption process or adsorption process respectively.

The outlet temperature of the working fluid from the major system components: adsorber, desorber, evaporator and condenser are estimated using the LMTD method [18] :

$$
T_{f, \text { out }}=\mathrm{T}+\left(\mathrm{T}_{\mathrm{f}, \text { in }}-\mathrm{T}\right) \exp \left(\frac{-\mathrm{U}_{\mathrm{des} / \mathrm{ad}} A_{\text {des } / a d}}{\dot{m}_{f} C p_{f}}\right)
$$

\section{- Condenser energy balance}

The balance equation for the condenser is written by the following equation:

$$
\begin{aligned}
& \left(m_{c d} \times C p_{c d}\right) \frac{d T_{c d}}{d t}=-m_{a} \frac{d w_{d e s}}{d t} L v \\
& -m_{a} C p_{r, v} \frac{d w_{d e s}}{d t}(T d e s-T c d)+\dot{m}_{c w} C p_{c w}\left(T_{c w, i n}-T_{c w, o u t}\right)
\end{aligned}
$$

Where the cooling water outlet temperature is equal to :

$$
T_{c w, \text { out }}=\mathrm{T}+\left(\mathrm{T}_{\mathrm{cw}, \text { in }}-\mathrm{T}\right) \exp \left(\frac{-\mathrm{U}_{\mathrm{cd}} A_{c d}}{\dot{m}_{c w} C p_{c w}}\right)
$$

\section{- Evaporator energy balance}

The balance equation for the evaporator is given by the following equation: 


$$
\begin{aligned}
& \left(m_{e v} \times C p_{e v}+m_{r, e v} \times C p_{r}\right) \frac{d T_{e v}}{d t}=-m_{a} L v \frac{d w_{a d}}{d t} \\
& -m_{a} \frac{d w_{\text {des }}}{d t} C p_{r}\left(T_{c d}-T_{e v}\right)+m_{\text {chw }} C_{\text {chw }}\left(T_{\text {chw,in }}-T_{\text {chw out }}\right)
\end{aligned}
$$

Where the chilled water outlet temperature is given by:

$$
T_{c h w, o u t}=\mathrm{T}_{\mathrm{ev}}+\left(\mathrm{T}_{\mathrm{chw}, \mathrm{in}}-\mathrm{T}_{\mathrm{ev}}\right) \exp \left(\frac{-\mathrm{U}_{\mathrm{ev}} A_{e v}}{\dot{m}_{c h w} C p_{c h w}}\right)
$$

\section{Mass balance}

Neglecting the gas phase, the mass balance equation for water is expressed as:

$$
\frac{d m_{r, e v}}{d t}=-\mathrm{m}_{\mathrm{a}}\left(\frac{\mathrm{dw}_{\mathrm{des}}}{\mathrm{dt}}+\frac{\mathrm{dw}_{\mathrm{ad}}}{\mathrm{dt}}\right)
$$

\section{System performance}

The performance of the adsorption chiller can be determined by the cyclic average cooling capacity (CACC), and the average cyclic thermal performance coefficient $\mathrm{COP}_{\text {th }}$, these parameters are calculated for one complete cycle time $\left(\mathrm{t}_{\text {cycle }}\right)$ which is the sum of adsorption time, preheating time, desorption time, and precooling time [4] :

$$
\begin{aligned}
C A A C & =\frac{\dot{m}_{\text {chw }} \int_{0}^{\text {tycle }} C p_{\text {chw }}\left(\mathrm{T}_{\text {chw,in }}-\mathrm{T}_{\text {chw out }}\right) d t}{t_{\text {cycle }}} \\
C O P_{t h} & =\frac{C A A C}{Q_{g n}}
\end{aligned}
$$

Where $\mathrm{Q}_{\mathrm{gn}}$ is the average cyclic generator heat, which is given by:

$$
Q_{g n}=\frac{\dot{m}_{f} \int_{0}^{\text {tcycle }} C p_{r}\left(\mathrm{~T}_{\mathrm{hw}, \mathrm{in}}-\mathrm{T}_{\mathrm{hw}, \mathrm{out}}\right) d t}{\text { tcycle }}
$$

\subsection{Results and discussion}

\subsubsection{Simulink modelling for adsorption chiller}

As shown by equations 1-15, the dynamic response of the adsorption cooling systems are governed by a set of ordinary differential equations. Various simulation tools have been reported in literature to simulate the dynamic response of these systems like Modelica, Java language, Fortran, Matlab programing, Transys. Generally, these simulation tools develop defined functions and additional subroutines for the analysis of thermal systems. Simulink is a dynamic solver that uses mathematical and signal blocks with minimum need for additional user coding [19][20]. Therefore, it is more robust for the analysis and comparative studies.

Fig.7 shows a schematic diagram of a Simulink model for a two-bed adsorption cooling system consisting of four main subsystems describing the governing equations for the two adsorber/desorber beds, condenser and evaporator.

\subsubsection{Model Validation and Results}

The proposed mathematical model was validated with the experimental data from the literature for a two bed adsorption chiller operating with a constant heat source temperature[21]. Fig. 8 displays a comparison between the measured values of the water outlet temperatures for the desorber, adsorber, condenser and evaporator with current simulation results. It is clear from this figure that, a good agreement between the experimental and simulation results was reached.

\subsubsection{Parametric study}

The property values and design parameters for adsorption chiller used in the simulation model are the same as Chua et al 1999 [15]. The system optimal performance depends basically on three important operating conditions which are the adsorption/regeneration cycle duration, regeneration temperature and cooling water inlet temperature. In this parametric analysis, optimum operating conditions are correlated in a wide range of a hot water inlet temperature $\left(55^{\circ} \mathrm{C}\right.$ to $\left.95^{\circ} \mathrm{C}\right)$, a cooling water inlet temperature $\left(25^{\circ} \mathrm{C}\right.$ to $\left.40^{\circ} \mathrm{C}\right)$ and half cycle time $(200 \mathrm{~s}$ to $500)$. Whereas chilled water inlet temperature is held constant at $15^{\circ} \mathrm{C}$.

The initial operating conditions of the two-bed adsorption chiller are listed in TABLE 1

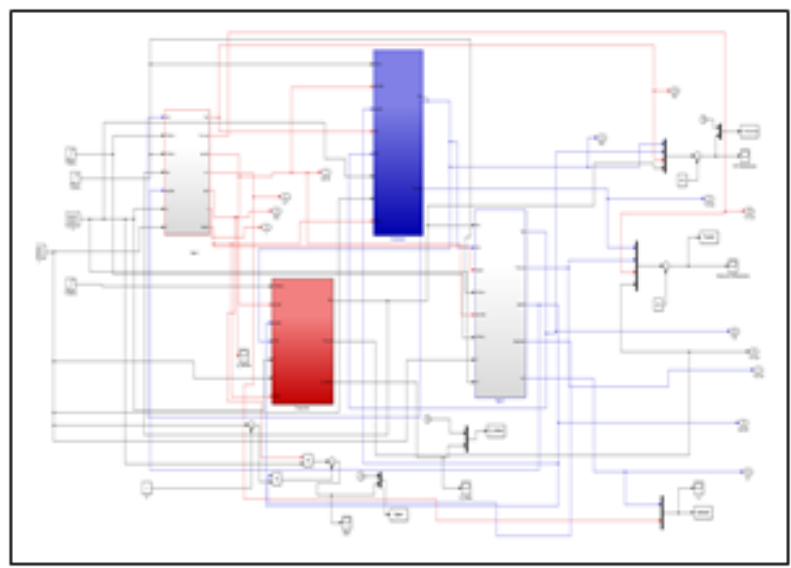

Fig.7. Arrangement of adsorption refrigerator component in Simulink simulation environment 


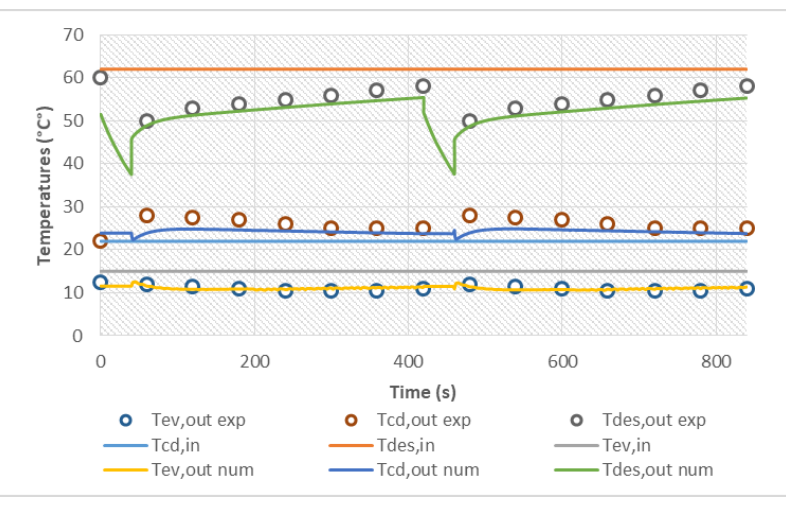

Fig. 8. Comparison between simulated and experimental water outlet temperature profiles.

TABLE 1. Cycle standard operating conditions

\begin{tabular}{lll}
\hline Physical parameter & Value & Units \\
\hline Chilled water supply & & \\
Hot water temperature & 15 & ${ }^{\circ} \mathrm{C}$ \\
Cooling water temperature & 85 & ${ }^{\circ} \mathrm{C}$ \\
Chilled water flow rate & 30 & ${ }^{\circ} \mathrm{C}$ \\
Hot water flow rate & 0.7 & $\mathrm{~kg} / \mathrm{s}$ \\
Condenser cooling water flow rate & 1.3 & $\mathrm{~kg} / \mathrm{s}$ \\
Adsorber cooling water flow rate & 1.6 & $\mathrm{~kg} / \mathrm{s}$ \\
Half cycle time & 420 & $\mathrm{~kg} / \mathrm{s}$ \\
Switching time & 30 & $\mathrm{~s}$ \\
& &
\end{tabular}

\section{Effect of cycle time}

Fig. 9 shows the effect of cycle time on the cooling capacity and COP of the chiller at the rated operating conditions. Hot, cooling and chilled water inlet temperatures are kept constant at 85,30 and $15^{\circ} \mathrm{C}$, respectively.

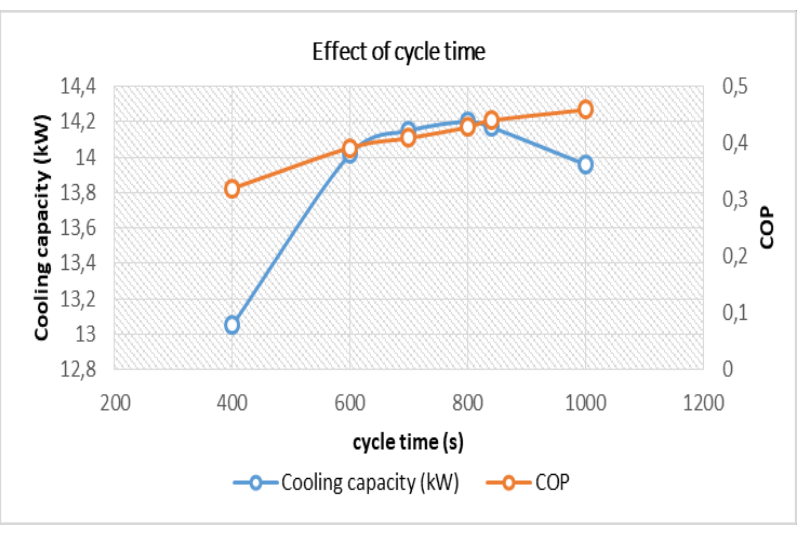

Fig. 9. Cycle time effects on refrigeration capacity and COP of Silica gel/water adsorption cooling cycle.

The cooling capacity increases with cycle time and has a maximum value of $14.2 \mathrm{~kW}$ at a cycle time of $800 \mathrm{~s}$. Then at cycle time longer than 800 seconds it decreases due to a less rate of adsorption because the adsorbent mass approaches to saturation conditions. The COP of the chiller increases uniformly with cycle time. The highest values of cooling capacity for silica gel/water pair were obtained when cycle time is between 700 seconds and 900 seconds means when adsorption/desorption time lies between 350 and 450 seconds.

\section{Effect of Hot Water Inlet Temperature}

To investigate the effect of the hot water inlet temperature on the system cooling capacity, cooling/chilled water inlet temperatures and half cycle time are taken constant at $25^{\circ} \mathrm{C}, 15^{\circ} \mathrm{C}$ and $840 \mathrm{~s}$, respectively.

As shown in Fig.10 the cooling capacity increases from $4 \mathrm{~kW}$ to $16.66 \mathrm{~kW}$ as the hot water inlet temperature is increased from $55^{\circ} \mathrm{C}$ to $95^{\circ} \mathrm{C}$. This is because a higher regeneration temperature leads to increase the amount of desorbed refrigerant and the evaporation of more refrigerant.

However, the values of COP show an increase for relatively higher heat source temperatures and decrease slightly for hot water inlet temperatures up to $85^{\circ} \mathrm{C}$. This means that the heat consumed to desorb the water from the silica gel becomes relatively higher than the generated cooling effect.

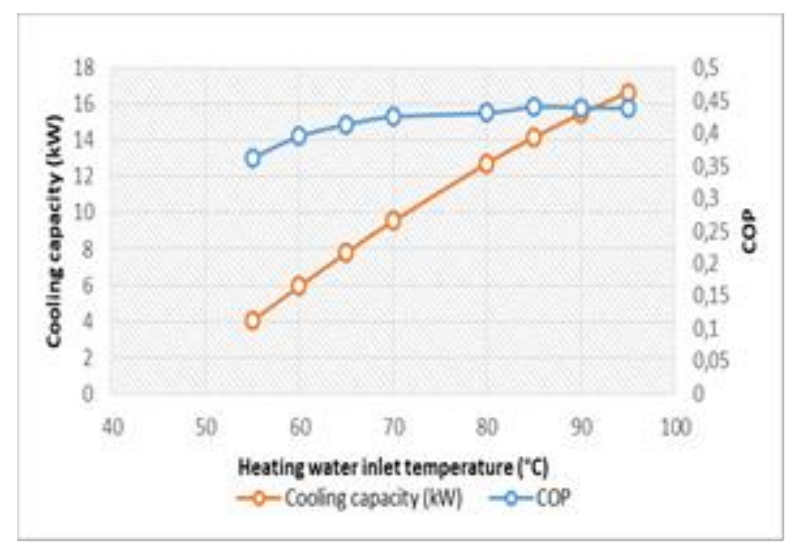

Fig.10. Hot water inlet temperature effects on refrigeration capacity and COP

\section{Effect of Cooling Water Inlet Temperature}

The effect of cooling water inlet temperature on both cooling capacity and COP is illustrated in Fig. 11.

Obviously, refrigeration capacity and COP decrease with the increase of cooling water inlet temperature.

The cooling capacity of the chiller decreases from 20.8 to $4.9 \mathrm{~kW}$ while the COP decreases from 0.5 to 0.25 when the cooling water inlet temperature increases from $22^{\circ} \mathrm{C}$ to $40^{\circ} \mathrm{C}$. This is because at lower adsorption temperatures, larger amount of refrigerant is adsorbed and as a result, a larger amount of refrigerant is desorbed 
during each cycle and a higher cooling capacity and COP.

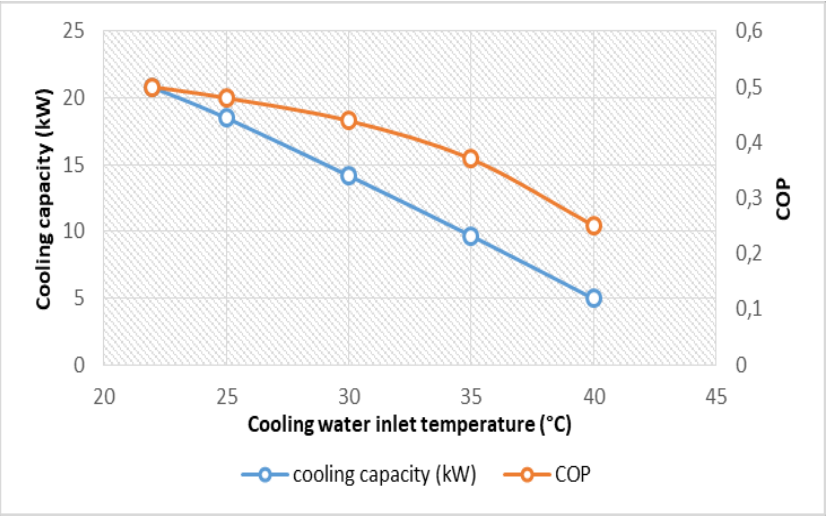

Fig. 11.Cooling water inlet temperature effects on refrigeration capacity and COP.

\section{Outlet temperature profile}

The outlet temperature profiles of each component of the chiller in optimum conditions (cycle time $=400$ seconds, cooling inlet temperature $=22{ }^{\circ} \mathrm{C}$ and heat inlet temperature $=85^{\circ} \mathrm{C}$ ) are presented in Fig.12. In these conditions for a COP equal to 0.52 , and cooling load of $22 \mathrm{~kW}$, the heat needed for the generator is $42.5 \mathrm{~kW}$.

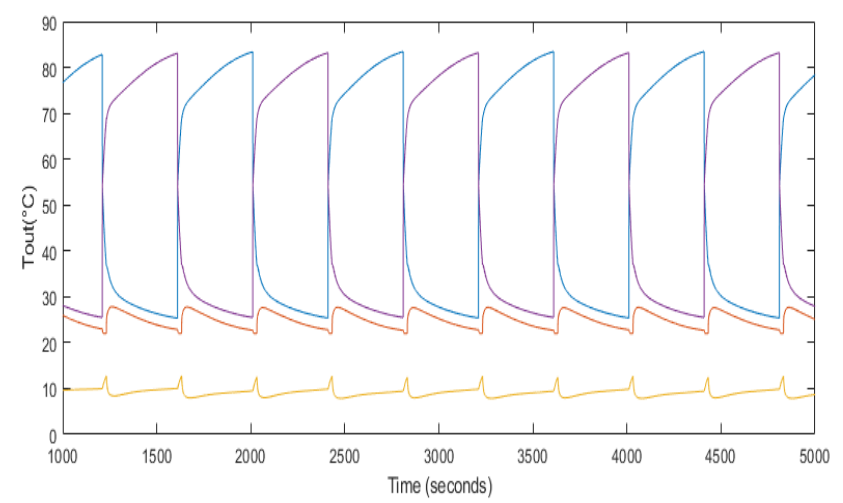

Fig.12. Outlet temperature profiles of different adsorption chiller components driven by constant heating source

\section{Conclusion}

This research demonstrated the capability of a two beds adsorption chiller to generate low air temperature in a cold storage room destined for preserving fruits and vegetables.

The following conclusions are drawn from the foregoing discussion:

- A parametric study aims to choose the optimum operating conditions should be done to find the best solutions for running an adsorption refrigeration system with high performance.
- A maximum average cooling power of $22 \mathrm{~kW}$ is obtained with a heat source generator of $42.5 \mathrm{~kW}$ power.

- The heating and cooling inlet temperatures influence the cooling capacity of the chiller more than the cycle time duration. However, this parameter influences most the reduction of the storage temperature, the outlet temperature of the evaporator decreases with the decrease of cycle time duration.

- Nevertheless, to adopt the adsorption based cooling system one needs to find solutions to supplement the heat source discontinuity.

\section{Acknowledgment}

This work was supported by PHC-Maghreb 19Mag29 project. We would like to thank also our Ministries and the research units LEMTA-LERMAB (university of Lorraine, France) and LR18ES35 (university of Gabes, Tunisia).

\section{Nomenclature}

\section{A Area $\left[\mathrm{m}^{2}\right]$}

$\mathrm{Cp} \quad$ Specific heat $[\mathrm{kJ} / \mathrm{kg}]$

$\mathrm{D}_{\text {so }} \quad$ Surface diffusion constant $\left[\mathrm{m}^{2} \mathrm{~s}^{-1}\right]$

$\mathrm{E}_{\mathrm{a}} \quad$ Activation Energy [ $\left.\mathrm{J} \mathrm{mol}^{-1}\right]$

$\mathrm{H}_{\mathrm{ads}} \quad$ Isosteric heat of adsorption [ $\mathrm{kJ} . \mathrm{kg}^{-1}$ ]

Fp Particle shape factor

m Mass [kg]

$\mathrm{m}_{\mathrm{a}} \quad$ Adsorbent mass $[\mathrm{kg}]$

$\dot{\mathrm{m}}$ Mass flow rate $[\mathrm{kg} / \mathrm{s}]$

$\mathrm{Q}_{\text {gen }} \quad$ The heat generator input $[\mathrm{kW}]$

$\mathrm{Q}_{\mathrm{ev}} \quad$ Cooling capacity of the evaporator $[\mathrm{kW}]$

$\mathrm{R} \quad$ Universal gas constant $=8.314\left[\mathrm{~J} \mathrm{~mol}^{-1} \mathrm{~K}^{-1}\right]$

$\mathrm{Rp} \quad$ Particle radius [m]

$\mathrm{T}$ Temperature [K]

t Time (s)

$\mathrm{U} \quad$ Overall heat transfer coefficient $\left[\mathrm{Wm}^{2} \mathrm{~K}^{-1}\right]$

w Instantaneous uptake $[\mathrm{kg} / \mathrm{kgads}]$

$\mathrm{W}^{*} \quad$ Equilibrium uptake $[\mathrm{kg} / \mathrm{kgads}]$

\section{Subscript}

a Adsorbant

ad Adsorber

cd Condenser

chw Chilled water

cw Cooling water to condenser

des Desorber

ev Evaporator

$f \quad$ Heating/Cooling fluid to desorber/adsorber

gen Generation

in Inlet

out Outlet

r Refrigerant

V Vapor

\section{References}

[1] J. M. Abdulateef, K. Sopian, M. A. Alghoul, M. Y. Sulaiman, Renew. Sust. Energy Rev., 13, 1338, (2009). 
[2] M. L. Ntsoane et al., Postharvest Biol. Technol., 149, 195, (2019).

[3] S. Furbo, L. J. Shah, and U. Jordan, Solar Energy :State of the art. (2003).

[4] A. R. M. Rezk and R. K. Al-Dadah, Appl. Energy, 89, 142, (2012).

[5] K. Habib, B. B. Saha, A. Chakraborty, S. Taek, and S. Koyama, Appl. Therm. Eng., 50; 1582 (2013).

[6] C. Y. Tso and C. Y. H. Chao, Int. J. Refrig., 35, 1626, (2012).

[7] B. Choudhury, B. Baran, P. K. Chatterjee, and J. Prakas, Appl. Energy, 104, 554, (2013).

[8] K. C. A. Alam, B. Baran, and A. Akisawa, Appl. Therm. Eng., 50, 1603, (2013).

[9] R. Carneiro, P. D. Gaspar, and P. D. Silva, Appl. Therm. Eng., 113, 585, (2017).

[10] A. Hmida, N. Chekir, A. Laafer, M. E. A. Slimani, and A. Ben Brahim, J. Clean. Prod., 211, 1239, (2019).

[11] A. S. Dalkilic, N. A. Kurekci, O. Kincay, and S. Wongwises, Arab. J. Sci. Eng., 38, 1115, (2013).

[12] ASHRAE HANDBOOK.Fundamentals, InchPound., 2, no. 1. (2009).

[13] D. R. Heldman and D. B. Lund, Handbook of food engineering, second edition, $2^{\text {nd }}$ ed. (2006).

[14] X. Wang and H. T. Chua, Int. J. Refrig., 30, 1417, (2007).

[15] H. T. Chua, K. C. Ng, A. Malek, T. Kashiwagi, A. Akisawa, and B. B. Saha, Int. J. Refrig., 22, 194, (1999).

[16] K. Chihara and M. Suzuki, J. Chem. Eng. Japan, 16, 293, (1983).

[17] R. P. Sah, B. Choudhury, and R. K. Das, Int. J. Sustain. Energy, 6451, (2016).

[18] A. K. Jaiswal, S. Mitra, P. Dutta, K. Srinivasan, and S. Srinivasa Murthy, Sol. Energy, 136, 450, (2016).

[19] A. Sadeghlu, M. Yari, S. M. S. Mahmoudi, and H. B. Dizaji, Int. J. Therm. Sci., 80, 76, (2014).

[20] G. Zhang, D. C. Wang, J. P. Zhang, Y. P. Han, and W. Sun, Sol. Energy, 85, 1469, (2011).

[21] N. Ghilen, S. Gabsi, S. Messai, R. Benelmir, and M. El Ganaoui, Case Stud. Therm. Eng., 8. 337, (2016). 